\title{
CYCLIC VOLTAMMETRY AND SHORT-TIME SCALE CHRONOAMPEROMETRY AT LAYER-BY-LAYER SELF-ASSEMBLED Au MODIFIED ELECTRODES. FRUCTOSE BIOSENSOR
}

\author{
IONEL CĂTĂLIN POPESCU ${ }^{a, *}$
}

\begin{abstract}
Cyclic voltammetry (CV) and short-time scale chronoamperometry measurements were performed aiming to investigate the layer-by-layer selfassembled multilayer structures built on Au electrodes. The attractive electrostatic interactions exerted between the successively deposited layers of charged polymers were exploited in order to immobilize a cationic Os redox polymer onto the surface of Au modified electrodes. CV responses observed at the resulted Au modified electrodes proved the efficiency of the proposed design. The chronoamperometric responses were fitted by using a three-phase exponential decay function. The fitting parameters allowed comparing the ability of charge transfer of the investigated modified electrodes. The most efficient structure was used as an amperometric transducer for electrical communication between fructose dehydrogenase and the Au electrode. In order to validate the new approach as a proof of concept for obtaining reagentless biosensors, a functional amperometric biosensor for D-fructose was successfully built.
\end{abstract}

Keywords. Self-assembled multilayer architecture, electrostatic interactions, Au modified electrodes, reagentless amperometric biosensors, Os redox polymer.

\section{INTRODUCTION}

Various approaches were proposed to obtain modified electrodes such as: chemisorption, covalent bonding, polymer film coating, and entrapment in a

\footnotetext{
a Babeş-Bolyai University, Faculty of Chemistry and Chemical Engineering, 11 Arany Janos str., RO-400028, Cluj-Napoca, Romania,

*Corresponding author: cpopescu@chem.ubbcluj.ro
} 
conductive material [1]. Among these, a simple way exploited the spontaneous formation of the self-assembled structures immobilized on the surface of a conducting material $[2,3]$. Conveniently handled, this approach yields modified electrodes covered by multilayer architectures, exhibiting high electrocatalytic activity and good selectivity and sensitivity $[4,5]$.

Recently, the electrostatic interaction exerted between oppositely charged monolayers was successfully used for the construction of biosensors incorporating self-assembled multilayer structures [6-12]. Thus, it was clearly demonstrated that multilayer architectures based on the alternation of a positively charged redox polymer and adequately charged polyelectrolytes yield, by simple successive self-deposition, electrochemical active platforms able to act as amperometric transducers for various biosensors used to detect: glucose [7, 10-12], hydrogen peroxide, methanol and D-fructose [12, 13].

In the present paper, a two-step method consisting in cyclic voltammetry coupled with short-time scale chronoamperometric measurements was used to examine the electrochemical behavior of the modified electrodes, built up by successive self-deposition of electrically charged layers. The CV responses were used to confirm the functionality of the modified electrodes preparation. The recorded chronoamperograms, were best fitted by using a three-phase exponential decay function $[14,15]$, and served to identify the most efficient structure. Finally, a reagentless amperometric biosensor for D-fructose amperometric detection was described.

\section{RESULTS AND DISCUSSION}

The typical voltammetric behavior of a clean $\mathrm{Au}$ surface was confirmed by the comparing the cyclic voltammogram recorded at cleaned Au wire electrodes in contact with $0.1 \mathrm{~N} \mathrm{H}_{2} \mathrm{SO}_{4}$ (Figure 1) with that published in the literature [16]. It is important to notice that the potential window located between 100 and $500 \mathrm{mV}$ versus $\mathrm{Ag} / \mathrm{AgCl}, \mathrm{KCl}_{\text {sat }}$ is well placed in the domain of the relative electrochemical inactivity of the Au surface.

The voltammetric responses observed at bare Au electrode as well as at Au modified electrodes based on various self-assembled architectures built up by using layer-by-layer deposition technique are shown in figure 2 . The scanned potential domain was selected such as it corresponds to the electrochemical activity of the $\mathrm{Os}^{+2 /+3}$ redox centers, incorporated in the OsRP structure [17]. 
CYCLIC VOLTAMMETRY AND SHORT-TIME SCALE CHRONOAMPEROMETRY AT LAYER-BY-LAYER SELF-ASSEMBLED Au MODIFIED ELECTRODES. FRUCTOSE BIOSENSOR

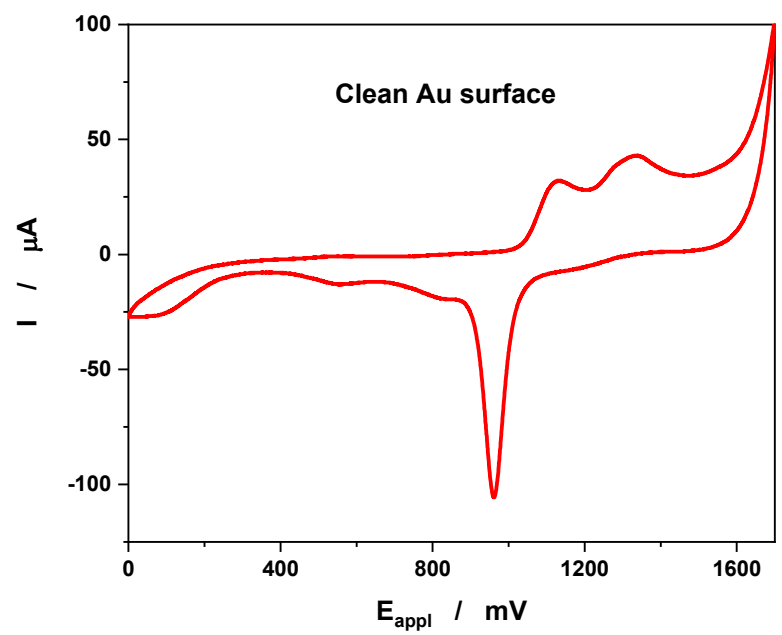

Figure 1. The voltammetric response recorded at clean Au electrodes. Experimental conditions: potential scan rate, $50 \mathrm{mv} / \mathrm{s}$; initial potential, $0 \mathrm{mV}$ versus $\mathrm{Ag} / \mathrm{AgCl}, \mathrm{KCl}$ sat; supporting electrolyte, $0.1 \mathrm{M} \mathrm{H}_{2} \mathrm{SO}_{4}$.

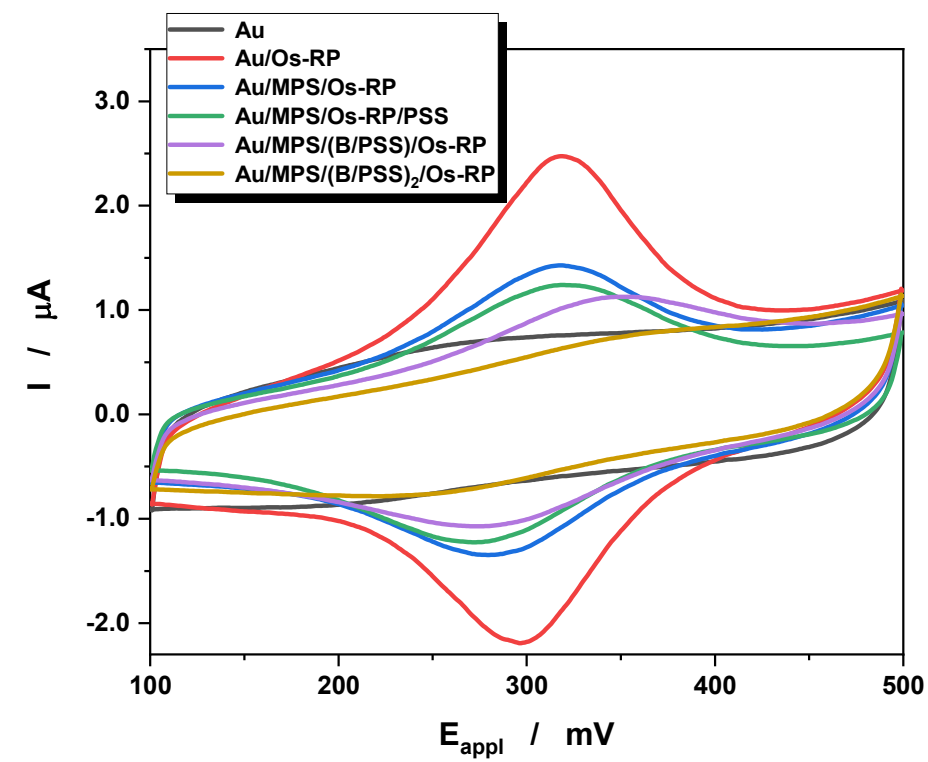

Figure 2. Cyclic voltammograms recorded at Au electrodes modified with different self-assembled monolayers based on self-deposited layers of Os-RP, MPS, PSS, and B. Experimental conditions: initial potential, $100 \mathrm{mV}$ versus $\mathrm{Ag} / \mathrm{AgCl}, \mathrm{KCl}$ sat; potential scan rate, $50 \mathrm{mV} / \mathrm{s}$; supporting electrolyte, $0.1 \mathrm{M}$ acetate buffer $(\mathrm{pH} 5.0)$ containing $0.15 \mathrm{M} \mathrm{NaCl}$. 
As can clearly be seen in figure 2 , the successive interposition of one or more nonconductive layers (such as MPS, B and PSS) between the Os redox centers and the Au electrode surface induce a gradual decrease of the voltammeytric response of the investigated electrodes. Obviously, this behavior is due to an increase of the distance between the redox partners generating the observed voltammetric response: the Au electrode and the $\mathrm{Os}^{+21+3}$ redox centers. At the same time, this peculiar comportment is an indirect proof, validating the reliability of the layer-by-layer self-assembling technique for obtaining modified electrodes based on complex multilayer structures [12]. It is worth mentioning that the layer-by-layer self-assembling technique, based on electrostatic interactions existing between oppositely charged polymers, offers a simple and direct possibility for fine-tuning of the sensitivity as well as the selectivity of the modified electrodes $[7,10]$.

Figures $3 \mathrm{~A}$ and $3 \mathrm{~B}$ depict the short-time scale chronoamperometric responses recorded at the investigated Au modified electrodes, immersed in the supporting electrolyte.

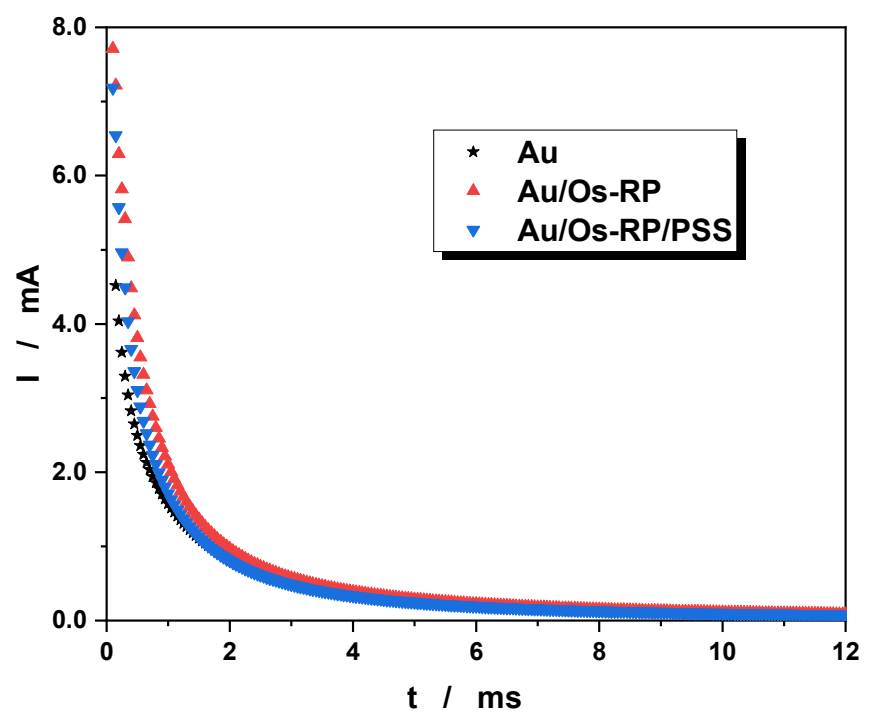

Figure 3A. Single potential step chronoamperograms recorded for cationic Osredox polymer adsorbed on bare Au electrodes. Experimental conditions: initial potential, $100 \mathrm{mV}$ versus $\mathrm{Ag} / \mathrm{AgCl}, \mathrm{KCl}$ sat; final potential, $100 \mathrm{mV}$ versus $\mathrm{Ag} / \mathrm{AgCl}, \mathrm{KCl}$ sat; supporting electrolyte, $0.1 \mathrm{M}$ acetate buffer ( $\mathrm{pH} 5.0$ ) containing $0.15 \mathrm{M} \mathrm{NaCl}$. Each experimental point represents the average of 10 consecutive measurements carried out at the same modified electrode. 


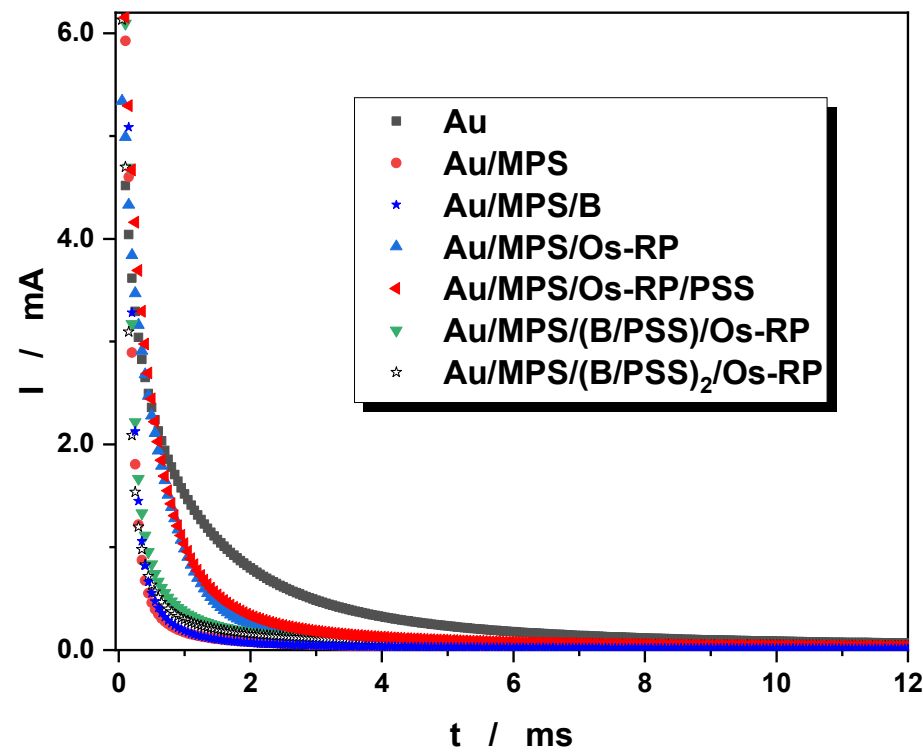

Figure 3B. Single potential step chronoamperograms recorded at different selfassembled Au/MPS electrodes. Experimental conditions: initial potential, $100 \mathrm{mV}$ versus $\mathrm{Ag} / \mathrm{AgCl}, \mathrm{KCl}$ sat; final potential, $100 \mathrm{mV}$ versus $\mathrm{Ag} / \mathrm{AgCl}, \mathrm{KCl}$ sat; supporting electrolyte, $0.1 \mathrm{M}$ acetate buffer ( $\mathrm{pH}$ 5.0) containing $0.15 \mathrm{M} \mathrm{NaCl}$. Each experimental point represents the average of 10 consecutive measurements carried out at the same modified electrode.

As a general conclusion, it can be stated that for all investigated electrodes a meaningful correlation between the intensities of the voltammetric and chronoamperometric responses occurs. Thus, the amplitude of the transient currents follows straightly the same pattern observed for cyclic voltammetry measurements.

At the same time, qualitatively, the increasing order of the global decay rates, noticed for the chronoamperometric responses of the investigated modified electrodes, listed in the following sequence:

\section{$\mathrm{Au} / \mathrm{Os}-\mathrm{RP}<\mathrm{Au} / \mathrm{Os}-\mathrm{RP} / \mathrm{PSS}<\mathrm{Au}<\mathrm{Au} / \mathrm{MPS} / \mathrm{Os}-\mathrm{RP} \approx \mathrm{Au} / \mathrm{MPS} / \mathrm{Os}-\mathrm{RP} / \mathrm{PSS}<$ Au/MPS/(B/PSS)/Os-RP $\approx A u / M P S /(B / P S S)_{2} / O s-R P<A u / M P S / B<A u / M P S$}

is in a good agreement with the voltammetric data shown in Figures $3 \mathrm{~A}$ and 3B. 
Aiming to obtain more information about the electrochemical behavior of the investigated modified electrodes, the recorded short-time scale chronoamperometric responses were fitted to a three-phase exponential decay function:

$$
\mathbf{Y}=\Sigma \mathbf{A}_{\mathrm{i}}^{*} \exp \left(-\mathbf{x} / \mathbf{t}_{\mathrm{i}}\right)(\mathrm{i}=1-3)
$$

This approach offers a simple way to split the global amperometric response recorded after a single potential step in its main components: capacitive, faradaic and diffusive $[14,15]$. The values of the $(A, t)$ parameter pairs were calculated by using a nonlinear fitting software (Origin 8.0) and are listed in Table 1.

Some interesting information was revealed when the variation of the $t_{1}$ parameter value was examined in correlation with the structural changes involved in the multilayer architecture existing on the Au electrode surface. Thus, within the limits of experimental error, the values of the $t_{1}$ parameter were found almost identical for Au/MPS/B, Au/MPS, Au/MPS/(B/PSS)/Os-RP, and Au/MPS/(B/PSS) $)_{2}$ Oss-RP modified electrodes, suggesting that in all these cases the charge transfer is the strongly hindered by the presence of nonconductive layers within the structure of the electrochemical interface.

Moreover, the Au/MPS/Os-RP, Au/Os-RP/PSS, and Au/MPS/OsRP/PSS electrodes, due to their high values of the $t_{1}$ parameter, can be considered as the most active among the investigated redox interfaces. Consequently, these electrodes are recommended to be used as electrochemical platforms for sensors/biosensors construction.

That is why, in a final step, FDH was immobilized on Au/MPS/Os-RP by using the electrostatic attraction exerted between the positively charged surface of the Au/MPS/Os-RP modified electrode and the negatively charged enzyme. The bioelectrocatalytic responses recorded at the resulted Au/MPS/Os-RP/FDH bioelectrodes for increasing concentrations of D-fructose are shown in figure 4 . The very well-shaped electrocatalytic responses, recorded at Au/MPS/Os-RP/FDH biosensor in presence of different D-fructose concentrations (Figure 4), doubtless confirm the efficient electrical communication established between FDH and the Au electrode surface, mediated by the presence of cationic Os-redox polymer.

Based on the experimental data shown in figure 4, the analytical parameters of the $D$-fructose biosensor were estimated as follows: linear range, up to $20 \mathrm{mM}$; sensitivity, $(0.185 \mathrm{~mA} / \mathrm{M})$; detection limit, $0.4 \mathrm{mM}$ D-fructose; reproducibility, better than 95\%; low susceptibility to electrochemical interferences, due to the low applied potential, and an acceptable stability (better than one month). 


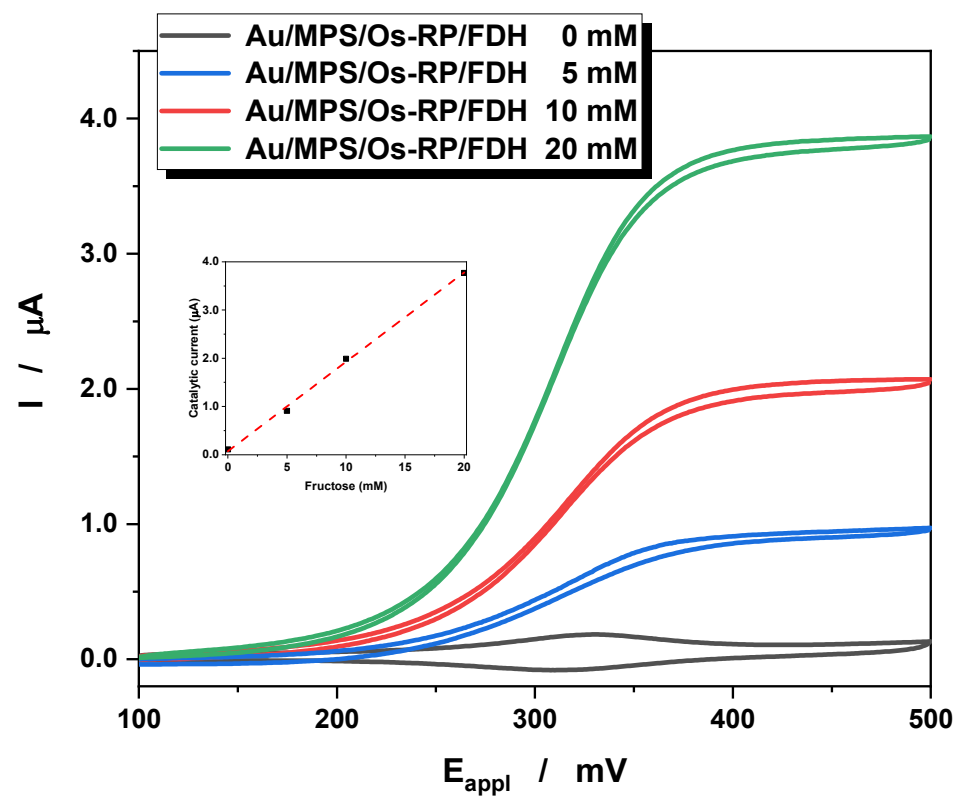

Figure 4. Cyclic voltammetry recorded at Au/MPS/Os-RP/FDH modified electrodes in presence of different concentrations of D-fructose. Experimental conditions: initial potential, $100 \mathrm{mV}$ versus $\mathrm{Ag} / \mathrm{AgCl}, \mathrm{KCl}$ sat; scan rate, $2 \mathrm{mV} / \mathrm{s}$; supporting electrolyte, $0.1 \mathrm{M}$ acetate buffer ( $\mathrm{pH} 5.0$ ) containing $0.15 \mathrm{M} \mathrm{NaCl}$.

This design can be considered as a promising proof of concept for a simple way to obtain reagentless amperometric biosensors.

\section{CONCLUSIONS}

Aiming to develop a simple and reliable method to monitor the selfassembled amperometric biosensors construction, cyclic voltammetry was coupled with short-time scale chronoampeometric measurements performed at modified electrodes based on multilayer architectures built up on attractive electrostatic interactions. A three-phase exponential decay function was used to fit the short-time scale chronoamperograms.

Finally, the applicability of the proposed method was demonstrated by the construction of a fully functional reagentless amperometric biosensor for $D$ fructose detection. 
Table 1. The fitting parameters corresponding to the chronoamperograms recorded at self-assembled Au modified electrodes. The experimental curves (Figures $2 \mathrm{~A}$ and $2 \mathrm{~B}$ ) were fitted to a three-phase exponential decay function: $\mathrm{Y}=\Sigma \mathrm{A}_{\mathrm{i}}^{*} \exp \left(-\mathrm{x} / \mathrm{t}_{\mathrm{i}}\right)$, where $\mathrm{i}=1,2,3$.

\begin{tabular}{|c|c|c|c|c|c|c|}
\hline \multirow[b]{2}{*}{ Electrode type } & \multicolumn{6}{|c|}{ Fitting parameters } \\
\hline & $\begin{array}{l}\mathrm{A}_{1} \\
\text { (A) }\end{array}$ & $\begin{array}{l}t_{1} \\
(s)\end{array}$ & $\begin{array}{l}\mathrm{A}_{2} \\
\text { (A) }\end{array}$ & $\begin{array}{l}t_{2} \\
(s)\end{array}$ & $\begin{array}{l}\mathrm{A}_{3} \\
\text { (A) }\end{array}$ & $\begin{array}{l}t_{3} \\
(s)\end{array}$ \\
\hline Au & $\begin{array}{c}\text { 3.0E-3 } \pm \\
1 \mathrm{E}-4\end{array}$ & $\begin{array}{c}2.9 \mathrm{E}-4 \pm \\
6 \mathrm{E}-6\end{array}$ & $\begin{array}{l}2.4 \mathrm{E}-3 \pm \\
7 \mathrm{E}-5\end{array}$ & $\begin{array}{c}1.4 \mathrm{E}-3 \pm \\
1 \mathrm{E}-4\end{array}$ & $\begin{array}{c}2.7 \mathrm{E}-4 \pm \\
4 \mathrm{E}-5\end{array}$ & $\begin{array}{c}\text { 7.5E-3 } \pm \\
1 \mathrm{E}-4\end{array}$ \\
\hline Au/MPS & $\begin{array}{c}1.1 \mathrm{E}-2 \pm \\
2 \mathrm{E}-3\end{array}$ & $\begin{array}{c}1.2 \mathrm{E}-4 \pm \\
2 \mathrm{E}-5\end{array}$ & $\begin{array}{l}5.9 \mathrm{E}-4 \pm \\
3 \mathrm{E}-4\end{array}$ & $\begin{array}{c}1.2 \mathrm{E}-3 \pm \\
\mathrm{E}-4\end{array}$ & $\begin{array}{l}\text { 7.4E-5 } \pm \\
5 \mathrm{E}-5\end{array}$ & $\begin{array}{c}1.4 \mathrm{E}-2 \pm \\
3 \mathrm{E}-3\end{array}$ \\
\hline Au/MPS/B & $\begin{array}{c}1.3 \mathrm{E}-2 \pm \\
1 \mathrm{E}-3\end{array}$ & $\begin{array}{l}1.3 \mathrm{E}-4 \\
\pm 1 \mathrm{E}-5\end{array}$ & $\begin{array}{c}3.4 \mathrm{E}-4 \pm \\
2 \mathrm{E}-4\end{array}$ & $\begin{array}{c}1.1 \mathrm{E}-3 \pm \\
2 \mathrm{E}-4\end{array}$ & $\begin{array}{c}2.6 \mathrm{E}-5 \pm \\
1 \mathrm{E}-5\end{array}$ & $\begin{array}{c}1.7 \mathrm{E}-2 \pm \\
5 \mathrm{E}-3\end{array}$ \\
\hline Au/Os-RP & $\begin{array}{l}6.4 \mathrm{E}-3 \pm \\
3 \mathrm{E}-4\end{array}$ & $\begin{array}{c}\text { 3.6E-4 } \pm \\
1 \mathrm{E}-5\end{array}$ & $\begin{array}{c}2.8 \mathrm{E}-3 \pm \\
3 \mathrm{E}-4\end{array}$ & $\begin{array}{c}1.50 \mathrm{E}-3 \pm \\
5 \mathrm{E}-5\end{array}$ & $\begin{array}{c}2.7 \mathrm{E}-4 \pm \\
2 \mathrm{E}-5\end{array}$ & $\begin{array}{c}\text { 1.12E-2 } \pm \\
7 \mathrm{E}-4\end{array}$ \\
\hline Au/Os-RP/PSS & $\begin{array}{c}6.4 \mathrm{E}-3 \pm \\
2 \mathrm{E}-4\end{array}$ & $\begin{array}{c}2.6 \mathrm{E}-4 \pm \\
1 \mathrm{E}-5\end{array}$ & $\begin{array}{c}2.2 \mathrm{E}-3 \pm \\
1 \mathrm{E}-4\end{array}$ & $\begin{array}{c}2.4 \mathrm{E}-3 \pm \\
2 \mathrm{E}-3\end{array}$ & $\begin{array}{l}8.1 \mathrm{E}-4 \pm \\
1 \mathrm{E}-4\end{array}$ & $\begin{array}{c}9.6 \mathrm{E}-3 \pm \\
1 \mathrm{E}-4\end{array}$ \\
\hline Au/MPS/Os-RP & $\begin{array}{c}5.8 \mathrm{E}-3 \pm \\
6 \mathrm{E}-4\end{array}$ & $\begin{array}{l}4.7 \mathrm{E}-4 \pm \\
2 \mathrm{E}-5\end{array}$ & $\begin{array}{c}6.0 \mathrm{E}-4 \pm \\
4 \mathrm{E}-4\end{array}$ & $\begin{array}{c}1.8 \mathrm{E}-3 \pm \\
6 \mathrm{E}-4\end{array}$ & $\begin{array}{l}\text { 4. } 3 \mathrm{E}-5 \pm \\
1 \mathrm{E}-5\end{array}$ & $\begin{array}{c}1.7 \mathrm{E}-2 \pm \\
2 \mathrm{E}-3\end{array}$ \\
\hline $\begin{array}{l}\text { Au/MPS/Os- } \\
\text { RP/PSS }\end{array}$ & $\begin{array}{l}\text { 7.6E-3 } \pm \\
1 \mathrm{E}-3\end{array}$ & $\begin{array}{c}3.4 \mathrm{E}-4 \pm \\
3 \mathrm{E}-5\end{array}$ & $\begin{array}{l}\text { 1.4E-3 } \pm \\
5 \mathrm{E}-4\end{array}$ & $\begin{array}{c}1.3 \mathrm{E}-3 \pm \\
2 \mathrm{E}-3\end{array}$ & $\begin{array}{l}9.2 \mathrm{E}-5 \pm \\
2 \mathrm{E}-5\end{array}$ & $\begin{array}{l}\text { 1.3E-2 } \pm \\
1 \mathrm{E}-3\end{array}$ \\
\hline $\begin{array}{l}\text { Au/MPS/B/PSS/ } \\
\text { Os-RP }\end{array}$ & $\begin{array}{c}1.2 \mathrm{E}-2 \pm \\
1 \mathrm{E}-3\end{array}$ & $\begin{array}{c}1.3 \mathrm{E}-4 \pm \\
1 \mathrm{E}-5\end{array}$ & $\begin{array}{c}7.9 \mathrm{E}-4 \pm \\
1 \mathrm{E}-4\end{array}$ & $\begin{array}{l}9.9 \mathrm{E}-4 \pm \\
9 \mathrm{E}-5\end{array}$ & $\begin{array}{c}8.9 \mathrm{E}-5 \pm \\
5 \mathrm{E}-6\end{array}$ & $\begin{array}{c}1.4 \mathrm{E}-2 \pm \\
6 \mathrm{E}-4\end{array}$ \\
\hline $\begin{array}{l}\text { Au/MPS/(B/PSS })_{2} / \\
\text { Os-RP }\end{array}$ & $\begin{array}{c}1.3 \mathrm{E}-2 \pm \\
2 \mathrm{E}-3\end{array}$ & $\begin{array}{c}1.2 \mathrm{E}-4 \pm \\
1 \mathrm{E}-5\end{array}$ & $\begin{array}{l}5.7 \mathrm{E}-4 \pm \\
9 \mathrm{E}-5\end{array}$ & $\begin{array}{c}1.0 \mathrm{E}-3 \pm \\
1 \mathrm{E}-4\end{array}$ & $\begin{array}{l}7.9 \mathrm{E}-5 \pm \\
8 \mathrm{E}-6\end{array}$ & $\begin{array}{l}2.0 \mathrm{E}-2 \pm \\
2 \mathrm{E}-3\end{array}$ \\
\hline
\end{tabular}

\section{EXPERIMENTAL SECTION}

\section{Reagents}

Au wires (0.5 min diameter, geometrical area ca. $0.16 \mathrm{~cm} 2,99.99 \%$ purity) were obtained from Goodfellow Cambridge (England). Sodium salt of 3-mercapto-1-propane sulfonic acid (MPS) and was purchased from Aldrich. The poly(styrene sulfonic acid) (MW 70,000; PSS) was used as received from Polyscience (Warrington, PA, USA). The cationic poly[(vinylpyridine)Os(bpy)2Cl] redox polymer partially quaternised with bromoethylamine (Os-RP) was synthesized as described elsewhere [18]. 
The positively charged polyelectrolyte, called binder (B), has the same structure as Os-RP except that no Os redox centers are present. Fructose dehydrogenase (FDH), from Gluconobacter sp., (EC 1.1.99.11, 34 $\mathrm{U} / \mathrm{mg}$ solid), was supplied by Sigma. D-Fructose was obtained from Fluka. All other chemicals used were of analytical grade. Water was obtained by means of a Millipore Milli-Q system.

\section{Equipment}

Cyclic voltammetry and chronoamperometry measurements were performed using a conventional three electrode electrochemical cell connected to a computer-controlled BAS CV-50W voltammetric analyzer (Bioanalytical Systems, West Lafayette, USA). All electrode potentials were measured against a potassium chloride saturated silver-silver chloride electrode $(\mathrm{Ag} / \mathrm{AgCl}, \mathrm{KCl}$ sat $)$. A coiled Pt wire served as counter electrode.

\section{Preparation of Au modified electrodes [12]}

Au wires, used as working electrodes, were successively polished by using fine, wet emery paper and $0.3-0.05 \mathrm{~mm}$ alumina (Buehler Inc.). Then, they were treated with freshly prepared 'piranha' (7:3 mixture of concentrated $\mathrm{H}_{2} \mathrm{SO}_{4}$ and $30 \% \mathrm{H}_{2} \mathrm{O}_{2}$ ) [Caution, piranha reacts violently with organic compounds!] for $30 \mathrm{~min}$. Finally, the Au wires were immersed for $2 \mathrm{~h}$ in a boiling saturated $\mathrm{KOH}$ solution. The cleaned Au wire electrodes were stored in concentrated $\mathrm{H}_{2} \mathrm{SO}_{4}$.

The Au/MPS modified electrodes were obtained by immersing the cleaned gold wire into a $1 \mathrm{mM}$ methanolic solution of MPS for $12 \mathrm{~h}$ and rinsing with pure ethanol.

The Au electrodes modified with multilayer supramolecular architectures (Au/Os-RP, Au/MPS/B, Au/Os-RP/PSS, Au/MPS/Os-RP, Au/MPS/OsRP/PSS; Au/MPS/B/PSS/Os-RP; Au/MPS/(B/PSS) ${ }_{2} /$ Os-RP) were prepared by sequential deposition of the adequate polyelectrolytes [6-9]. The alternate immersion of the Au/MPS modified electrodes in the corresponding aqueous polyelectrolyte solutions was carried out at room temperature while stirring vigorously by using the following aqueous solutions:

$-20 \mathrm{mg}$ of Os-RP/ml for Os-RP deposition (2 h);

$-25 \mathrm{mg}$ of PSS/ml for PSS deposition (1 h);

$-10 \mathrm{mg}$ of $\mathrm{B}$ for $\mathrm{B}$ deposition (2 h).

The fructose bioelectrodes, Au/MPS/Os-RP/FDH were prepared by FDH deposition on the surface of the multilayer modified electrode (Au/MPS/Os-RP) by simple adsorption $\left(2 \mathrm{~h}\right.$ at $4^{\circ} \mathrm{C}$, without stirring) from a $1 \mathrm{mg} / \mathrm{ml}$ FDH solution, dissolved in $0.1 \mathrm{M}$ acetate buffer ( $\mathrm{pH} 5.0)$. 


\section{ACKNOWLEDGMENTS}

The author acknowledges financial support from a NATO scholarship (1998). At the same time, the author gratefully acknowledges Dr. Elena Domínguez and Dr. Arantzazu Nárvaez for the useful discussions during his stage at the Department of Analytical Chemistry, Faculty of Pharmacy, University of Alcala de Henares, Spain.

\section{REFERENCES}

1. G. A. Edwards, A. J. Bergren, M. D. Porter, "Chemically Modified Electrodes", p. 295-327, in Handbook of Electrochemistry, Zoski, C. (ed), Elsevier Science, Amsterdam, The Netherlands, 2006

2. A. Ulman, Chem. Rev., 1996, 96, 1533-1554

3. A. L. Eckermann, D. J. Feld, J. A. Shaw, T. J. Meade, Coord. Chem. Rev., 2010, 254, 1769-1802

4. D. Schlereth, Compr. Anal. Chem., 2005, 44, 1-63

5. R. S. Freire, Ch. A. Pessoa, L. T. Kubota, Quim. Nova, 2003, 26, 381-389

6. G. Decher, J. D. Hong, Makromol. Chem. Macromol. Symp., 1991, 46, 321-327

7. Y. Lvov, K. Anga, I. Ichinose, T. Kunitake, J. Am. Chem. Soc., 1995, 117, 61176123

8. D. Laurent, J.B. Schlenoff, 1997, 13, 1552-1557

9. F. Caruso, K. Nlikura, D. N. Furlong, Y. Okahata, Langmuir, 1997, 13, 34223426

10. J. Hodak, R. Etchenique, E. J. Calvo, K. Singhal, P. N. Bartlett, Langmuir, 1997, 13, 2708-2716

11. H. Shi-Feng, Y. Ke-Sheng, F. Hui-Qun, Ch. Hong-Yuan, Talanta, 1998, 47, 561567

12. A. Nárvaez, G. Suarez, I. C. Popescu, I. Katakis, E. Domínguez, Biosens. Bioelectron., 2000, 15, 43-52

13. U. B. Trivedi, D. Lakshminarayana, I. L. Kothari, P. B. Patel, C. J. Panchal, Sens. Actuators B Chem., 2009, 136, 45-51

14. R. J. Forster, Analyst, 1996, 121, 733-741

15. R. J. Forster, Anal. Chem., 1995, 67, 1232-1239

16. L. D. Burke, P. F. Nugent, Gold Bull., 1997, 30, 43-53

17. I. Katakis, "Development and analysis of operation of enzyme electrodes based on electrochemically 'wired' oxidoreductases". PhD Thesis, 1994, University of Texas at Austin, USA

18. I. Katakis, A. Heller, Anal. Chem., 1992, 64, 1008-1013 